\title{
Jean-Paul Sermain, Le Conte De Fées. Du Classicisme Aux Lumières
}

\section{Paola Perazzolo}

\section{(2) OpenEdition}

1 Journals

\section{Edizione digitale}

URL: http://journals.openedition.org/studifrancesi/27577

DOI: 10.4000/studifrancesi. 27577

ISSN: 2421-5856

\section{Editore}

Rosenberg \& Sellier

\section{Edizione cartacea}

Data di pubblicazione: 31 décembre 2006

Paginazione: 600-601

ISSN: 0039-2944

\section{Notizia bibliografica digitale}

Paola Perazzolo, « Jean-Paul Sermain, Le Conte De Fées. Du Classicisme Aux Lumières », Studi Francesi [Online], 150 (L | III) | 2006, online dal 30 novembre 2015, consultato il 08 novembre 2020. URL : http:// journals.openedition.org/studifrancesi/27577 ; DOI : https://doi.org/10.4000/studifrancesi.27577

Questo documento è stato generato automaticamente il 8 novembre 2020.

\section{(c) $(1) \&$}

Studi Francesi è distribuita con Licenza Creative Commons Attribuzione - Non commerciale - Non opere derivate 4.0 Internazionale. 


\title{
Jean-Paul Sermain, Le Conte De Fées. Du Classicisme Aux Lumières
}

\author{
Paola Perazzolo
}

\section{NOTIZIA}

JEAN-PAUl SERmain, Le Conte De Fées. Du Classicisme Aux Lumières, Paris, Desjonquères, 2005, Pp. 284.

1 Specialista delle forme narrative di Ancien Régime, già editore della traduzione di Galland delle Mille et une nuits, nel presente volume J.-P. Sermain si interessa ai contes de fées, per la prima volta esaminati in tutta la loro diversità e unità al tempo stesso. L'autore prende infatti in considerazione non solo i testi di Perrault, o i licenziosi adattamenti di Galland, ma tutti i contes quali appaiono dal 1690, loro data di nascita, fino al 1760, quando il genere perde molte delle sue caratteristiche letterarie, evolvendo nella letteratura fantastica. Pur evocando successive trasformazioni, il testo non segue un percorso strettamente cronologico o tematico. Questo al fine di evidenziare l'unità poetica di un genere quanto a significati morali ed estetici, effetti sul lettore, proprietà letterarie. Nella prima parte, «Les Ambitions des conteurs», J-P. Sermain mostra infatti come, contrariamente a quanto potrebbe pensare il lettore moderno, queste opere si situassero al centro dei grandi dibattiti letterari della loro epoca - modalità e ruolo della creazione, uso della razionalità e suo rapporto all'alterità, rapporti con il romanzo, genere in divenire. Nella seconda parte, «Le conteur et son public», l'autore spiega in che modo il pubblico sia indotto ad adottare un ruolo e, di fatto, una "morale" ben precisi, per poi passare a prendere in esame nella sezione finale - «Poétique de l'imaginaire» - il marchio distintivo del genere, cioè le forme e i valori del suo immaginario.

2 Grazie a un'analisi puntuale e interessante, J-P. Sermain ristabilisce efficacemente il valore letterario di opere ancora oggi relegate al di fuori dei confini della letteratura perché erroneamente considerate come destinate a un pubblico infantile. 
Paradossalmente conosciute da tutti, esse sono però da tutti ignorate nella loro versione originale, ben più complessa e audace, che veicola in modo molto moderno temi percepiti come legati al passato poiché ripresi da fonti popolari, da romanzi medioevali, dal meraviglioso esotico di paesi stranieri. Modernità tematiche e formali, dunque, che caratterizzano un genere percepito come paritario rispetto alle altre forme narrative dell'epoca e a cui vengono attribuiti valori originali e a volte anche contestatari a livello sociale e letterario.

3 Scritto in modo brillante e piacevole, il volume di Sermain esamina i contes de fées da una prospettiva interessante e originale, che ha il pregio di non essere limitata per autore (Perrault, Mme d'Aulnoy, o le conteuses, la cui produzione è stata spesso analizzata da un punto di vista prevalentemente femminista), tema o metodologia, ma di essere tesa a ricostruire la «raison poétique, historique et anthropologique» (p. 10) di un genere che l'autore vuole inserire nel contesto letterario dell'epoca. A tal fine, il critico si propone di reperire, attraverso «les déclarations des auteurs, leurs choix thématiques et stylistiques, leurs rapports aux discussions contemporaines, [...] quel sens a pu avoir la création du conte de fées à la fin du XVII e siècle, ce qu'il a représenté de neuf, de provoquant même, quels types d'expériences il entendait explorer, mais aussi quels moyens spécifiques il s'est donnés, fort différents de ceux du roman contemporain et même des fables» (ibid.). In modo chiaro e preciso, J.-P. Sermain ci guida dunque alla scoperta di testi da considerare non più come legati solamente al folklore o all'interpretazione psicanalitica, ma come opere letterarie, e a quella di un mondo dove il dettaglio può evocare il meraviglioso, ma anche - o soprattutto rimandare all'attualità, sociale o letteraria che sia. 